\title{
The Effect of Phased Array Parameters on the Detecting Accuracy of Welding Discontinuities and 3D Measurement
}

\author{
Ahmed Mazloum $^{a}$, Ahmed Mahrous $^{a}$, Alber Alphonse Sadek ${ }^{b}$, Abd ElRahman Mohamed Moussa $^{a}$ \\ (a) Mechanical Engineering Department, Helwan University, Helwan, Egypt. \\ (b) Edison Welding Institute, EWI, Ohio, USA
}

\begin{abstract}
The reliable detection of defects is one of the most important tasks in nondestructive tests, mainly in the radiography test (RT) and ultrasonic test (UT). Non-Destructive Testing (NDT) is the most efficient as internal and external discontinuities are inspected while maintaining the target's original structure (form and function). Therefore, in this paper, the Phased Array Ultrasonic Testing (PAUT) method was applied to propose inspection method that can address certain key PAUT Parameters and image processing to enhance the precision of discontinuities and the reliability of calculations of discontinuity size and characterization and also transfer 2D S-Scan images into 3D images (volumetric scan) which is more reliable and easily interpretation.
\end{abstract}

Keywords : Welding discontinuities, Phased Array, Image Processing.

\section{Introduction \& Problem Description}

Phased Array Ultrasonic Test (PAUT) has gone from being a simple laboratory curiosity to an essential tool in industry. With the considerable increase in competition among industries, the quality control of equipment and materials has become a basic requisite to remain competitive in national and international markets. Although it is one of the new techniques of Ultrasonic method. PAUT is still accepted as essential for the control of welded joints in many industries such as the nuclear, naval, chemical or Oil and Gas. Most of welded joints failures are due to inaccurate interpretation (determination, sizing, measuring and evaluation) of their defects. So, the objective of this paper to increase the accuracy of detecting welding discontinuities measurement and interpret the S-scan images into 3D (volumetric scan) which is more reliable than 2D (S-scan). 


\section{Previous Work}

Phased array has developed well in the last several years, particularly for weld inspections to overcome the limitations of radiography inspections, and the importance of ultrasonic is rapidly replacing radiography worldwide especially automatic ultrasonic test (AUT) used phased arrays technique as the latest development in AUT and present major improvements over conventional multiprobe ultrasonics for gas pipeline girth weld \& pressure vessel inspection respectively as reported by Michael and Ginzel [1], Moles and Noel [2].

In 2008, Poirier and Ward [3] used the same device for research here "Phasor-XS" and proposed to use Performance Demonstration Initiative (PDI) process where a technique and technician is verified to be capable of finding and characterizing target defects with a very small margin of error and increasing Probability of Detection (POD). Bokaba and Mabuza [4] used also "Phasor-XS" to ensure the accuracy depths and sizes of defects in thick section welds of $25 \mathrm{~mm}$. According to Marefat and Faghedi [5] researches reported that there would be no defect on radiographic images which it is not be able to be detected by Phased Array ultrasonic technique. In most cases especially in detection of subtle welding defects the Phased Array ultrasonic technique is more reliable than RT. Also, it can be concluded that Phased Array Ultrasonic has no limitation to detection of surface longitudinal cracks in comparison with conventional Ultrasonic test while same frequency transducer can be used for dissimilar joint containing stainless steel 304 and simple carbon steel.

The geometry of a weld is an important factor for determining which angle to use for inspection in ultrasonic testing. The phased array sectorial scan makes it possible to scan areas with restricted access and also enables angles to be changed according to the geometry of the weld under inspection. Phased array systems allow inspection angles to be adjusted accurately and modified easily so as to obtain better response from defects [6].

So, the objective of this paper to develop :

- Phased Array results in 3D instead of 2D, to improve the characterization of welding discontinuities (Volumetric Scanning).

- An artificial intelligent model ANN to characterize arc welding discontinuities.

- Automatic system for detecting discontinuity type to eliminate Human error.

\section{Proposed System}

Fig.1 shows the equipment and instrumentation, that are used in the experiment, and it consists of the following : 


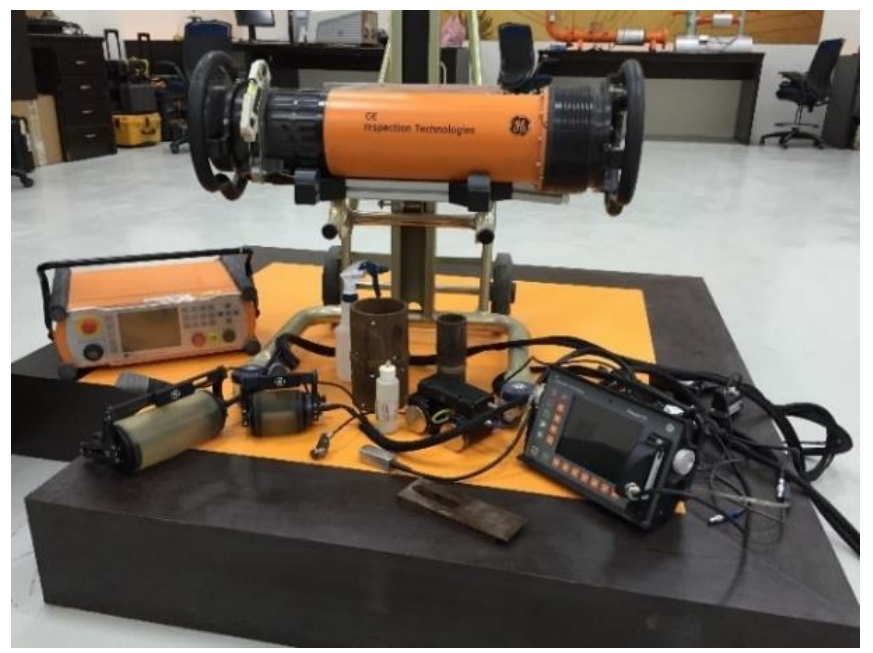

Fig.(1). Photo RT\&UT Equipment used.

\subsection{For radiography test (RT)}

- X-Ray BHGE-Generator - Eresco MF4 160kv,

- Computerized Radiography (CR) System : CRxFlex,

- CR Phosphor image plates IPC2, IPS with different sizes $10 \times 24 \& 10 \times 40 \mathrm{~cm} \&$ $10 \times 48 \mathrm{~cm}$,

- Rhythm Software.

\subsection{For ultrasonic test (UT)}

- Phased Array KRAUTKRAMER "Phasor-XS" unit (BHGE Inspection Technologies),

- Different Probes/wedges 2-4MHz $\left(35^{\circ}-75^{\circ}\right)$ with 8-64 elements,

- RotoArray probes $(5 \mathrm{MHz} / 64$ element $/ 0.8 \mathrm{~mm}$ pith $\times 6.4 \mathrm{~mm}$ width),

- RotoArray probes $(5 \mathrm{MHz} / 64$ element $/ 1.27 \mathrm{~mm}$ pith $\times 8 \mathrm{~mm}$ width),

- PATH Scanner and Alstom Inspection robotics,

- V1, V2, Stepped, AWS Resolution and PA-DM METRED Calibration blocks,

- Gel and Water is used as a couplant.

\subsection{Welding joints}

Figs.(2 and 3) show a photograph for the different specimens used. And all listed in table contains the profile and number of defects. The program of this research work was conducted in two different laboratories, i.e. two groups A and B. The first group (A) was chosen from PETROJET and MASSA workshops and different projects sites, representing a wide range of welding defects. The second group (B), was prepared at Abdullah-Fouad Application center. In this group the welding parameters were monitored, for several welding defects. 

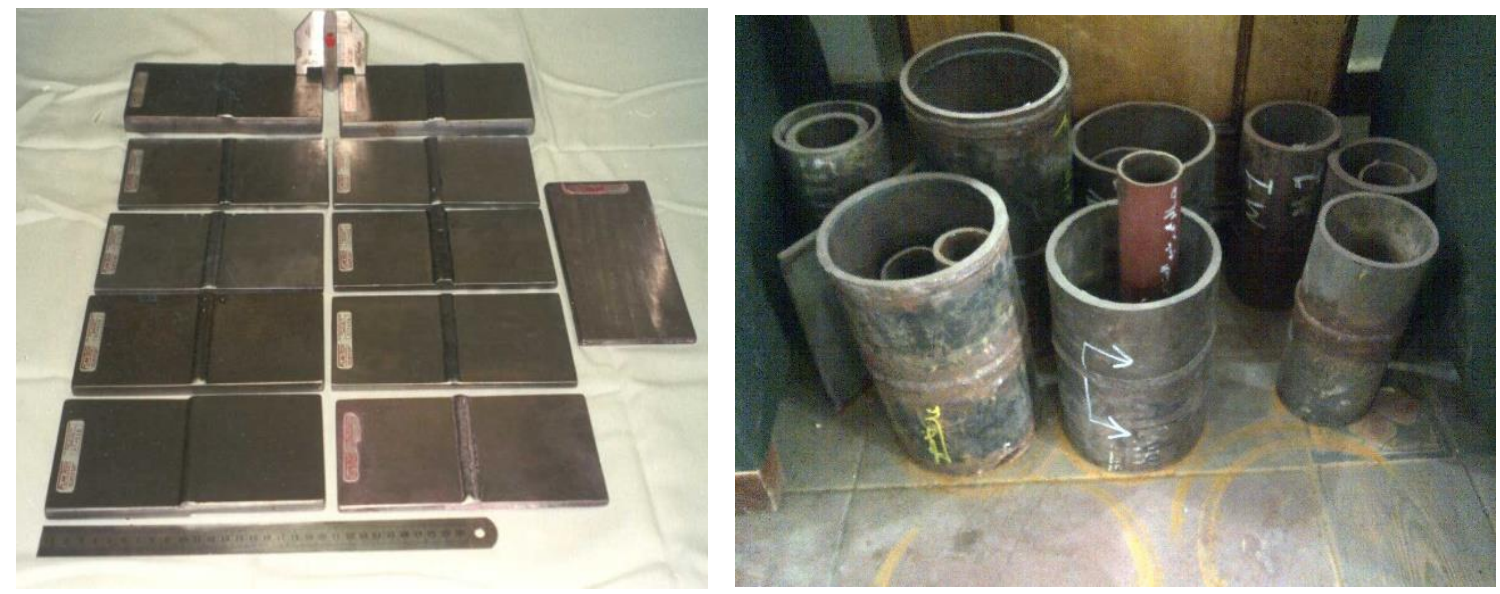

Fig.(2) Photograph of group(A): PETROJET\&MASSA butt welded joints with standard \& Practical Discontinuities.
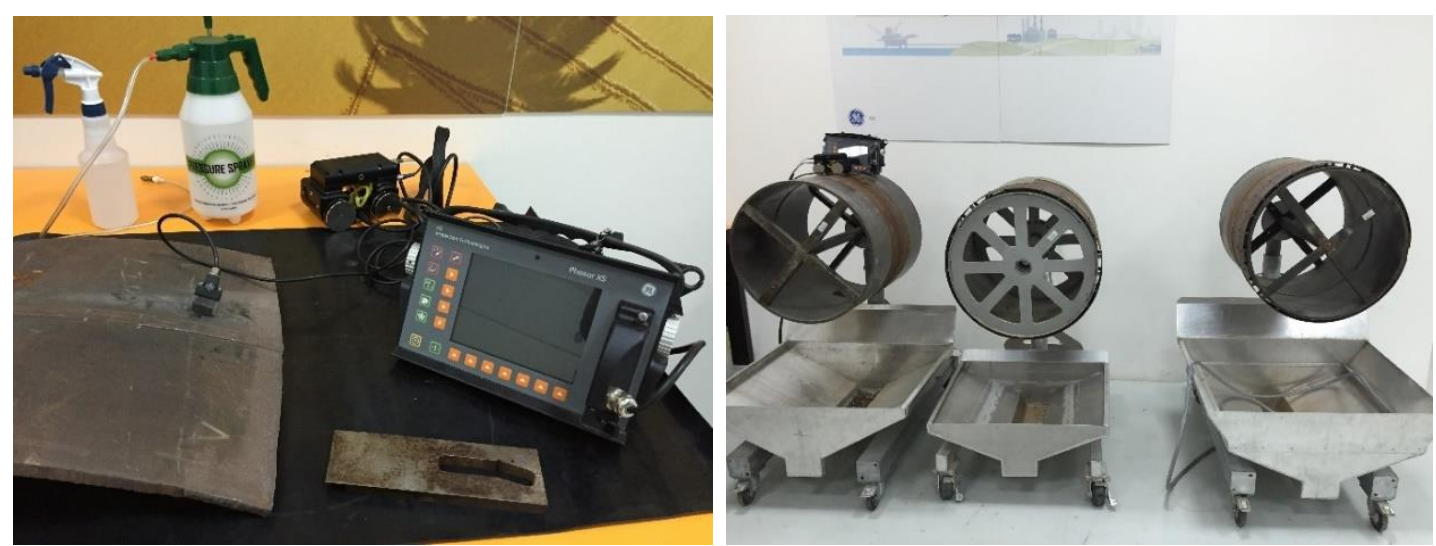

Fig.(3) Photograph of group (B): Abdullah Fouad's butt welded joints.

The welding joint direction was determined by measuring horizontally along the $\mathrm{X}$ axis from the starting point (left end) of the material to the starting point of the discontinuity and then by measuring vertically along the Y-axis from the center of the weld bead (either positively or negatively). The discontinuity length was then measured from the beginning to the end point in the $\mathrm{X}$-axis direction and the width from the same points but in the $\mathrm{Y}$-axis direction. The defect depth was measured from the top surface towards the beginning of the discontinuity in the Z-direction. As shown in Fig.(4). 


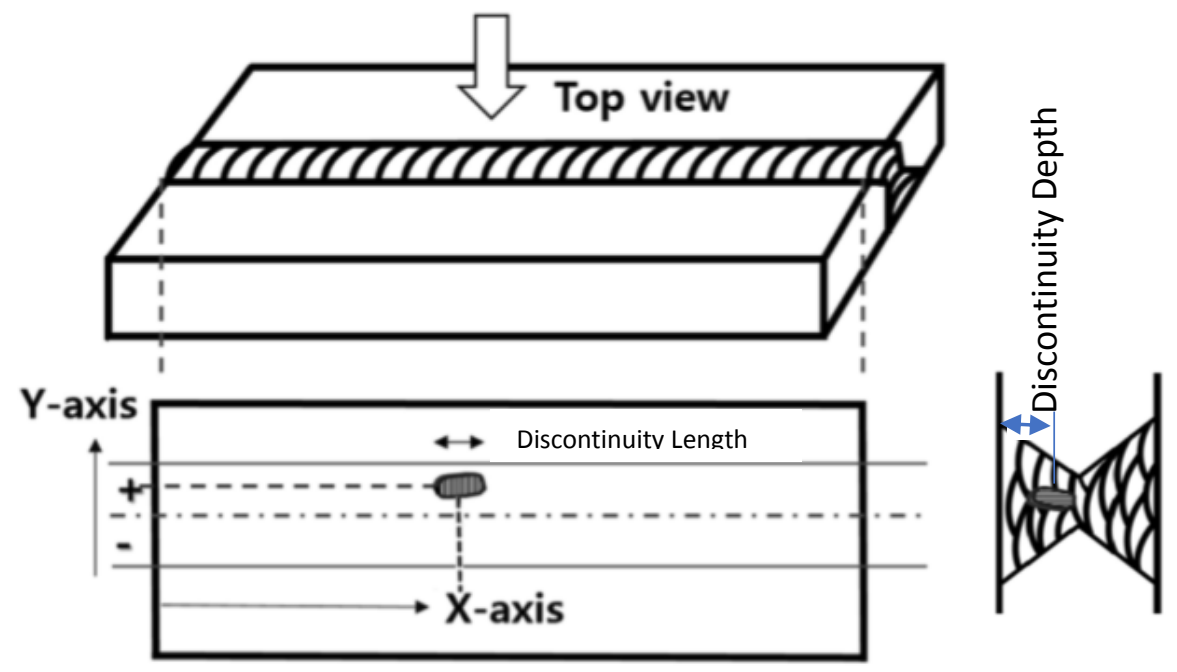

Fig.(4). Measuring length, width and depth of welding discontinuity in $\mathrm{X}, \mathrm{Y}$ and $\mathrm{Z}$ directions.

\section{Experimental Work}

\subsection{Analysis of method for the calculation of discontinuity length using acoustic pressure drop}

Using signals from a PAUT probe, the length of the discontinuity was measured by moving from the point yielding the maximum echo amplitude to $50 \%$ or $1 / 2(6 \mathrm{~dB})$. The length of each defect was additionally calculated for each drop method $(6 \mathrm{~dB}, 12 \mathrm{~dB}$ or overall) as shown in table (1). By using the results, the method used to assess the discontinuity length of the welds was analyzed.

The $6 \mathrm{~dB}$ drop yielded the most accurate results, and is therefore the most reliable. The $12 \mathrm{~dB}$ and the overall drop resulted in greater variances as a result of including the lengths of nearby discontinuities.

Table (1) Measuring results of defect length.

\begin{tabular}{|l|c|c|c|c|c|c|c|}
\hline $\begin{array}{c}\text { Discontinuity } \\
\text { Type }\end{array}$ & $\begin{array}{c}\text { Real } \\
\text { Measurements }\end{array}$ & $\begin{array}{c}\mathbf{6} \mathbf{d B} \\
(\mathbf{m m})\end{array}$ & $\begin{array}{c}\text { Deviation } \\
(\mathbf{\pm m m})\end{array}$ & $\begin{array}{c}\mathbf{1 2} \mathbf{~ d B} \\
(\mathbf{m m})\end{array}$ & $\begin{array}{c}\text { Deviation } \\
( \pm \mathbf{m m})\end{array}$ & Fully $(\mathbf{m m})$ & $\begin{array}{c}\text { Deviation } \\
( \pm \mathbf{m m})\end{array}$ \\
\hline $\begin{array}{l}\text { Incomplete } \\
\text { Penetration }\end{array}$ & 6.5 & 6.0 & -0.5 & 7.0 & +0.5 & 11.0 & +4 \\
\hline Crack & 23 & 24.0 & +1.0 & 26.0 & +3.0 & 28.0 & +5 \\
\hline Porosity & 10.5 & 11.0 & +0.5 & 13.0 & +2.5 & 15.0 & +4.5 \\
\hline Lack of Fusion & 161 & 162.0 & +1.0 & 164.0 & +3.0 & 168.0 & +6.0 \\
\hline Porosity & 23 & 24.0 & +1.0 & 28.0 & +4.0 & 30.0 & +7.0 \\
\hline Slag & 19 & 20.0 & +1.0 & 24.0 & +5.0 & 26.0 & +7.0 \\
\hline
\end{tabular}




\subsection{Effect of frequency $(F)$}

In the experiments of discontinuities measurements (length and width), four experiments $(2,2.25,4$ and 5) $\mathrm{MHz}$ were carried out, at Thickness $=20 \mathrm{~mm}$, velocity $=$ $5920 \mathrm{~m} / \mathrm{s}, \mathrm{n}$ (number of elements $)=16$ piezoelectric element, e (element width) $=$ $0.5 \mathrm{~mm}, \rho$ (pitch) $=0.5 \mathrm{~mm}, \mathrm{~g}$ (element gap) $=0.1 \mathrm{~mm}$. The length $/$ depth readings are listed in Table (2):

Table (2) The length readings for $F=(2,2.25,4$ and 5) MHz.

\begin{tabular}{|c|c|c|c|c|c|}
\hline \multicolumn{2}{|r|}{ Discontinuity Type } & $2 \mathrm{MHz}$ & 2.25 MHz & $4 \mathrm{MHz}$ & $5 \mathrm{MHz}$ \\
\hline \multirow{4}{*}{ (2) Crack } & Length Reading (9mm) & 9.7 & 9.5 & 9.3 & 9.2 \\
\hline & Error L & +0.7 & +0.5 & +0.3 & +0.2 \\
\hline & Depth Reading (6.5mm) & 6.2 & 6.3 & 6.4 & 6.5 \\
\hline & Error D & -0.3 & -0.2 & -0.1 & 0 \\
\hline \multirow{4}{*}{ (3) Porosity } & Length Reading (24mm) & 23 & 23.5 & 24.2 & 24.1 \\
\hline & Error L & -1.0 & -0.5 & +0.2 & +0.1 \\
\hline & Depth Reading (6.6mm) & 6.2 & 6.3 & 6.4 & 6.5 \\
\hline & Error D & -0.4 & -0.3 & -0.2 & -0.1 \\
\hline \multirow{4}{*}{ (5) Slag } & Length Reading (162mm) & 160.2 & 160.6 & 161.7 & 161.9 \\
\hline & Error L & -1.8 & -1.4 & -0.3 & -0.1 \\
\hline & Depth Reading (5mm) & 5.5 & 5.4 & 5.2 & 5.1 \\
\hline & Error D & +0.5 & +0.4 & +0.2 & +0.1 \\
\hline \multirow{4}{*}{$\begin{array}{l}\text { (17) Lack of } \\
\text { Penetration }\end{array}$} & Length Reading (162mm) & 163.7 & 163.2 & 162 & 162.5 \\
\hline & Error L & +1.7 & +1.2 & +1.0 & +0.5 \\
\hline & Depth Reading $(7.1 \mathrm{~mm})$ & 6.5 & 6.6 & 6.9 & 7.3 \\
\hline & Error D & -0.6 & -0.5 & -0.2 & +0.2 \\
\hline
\end{tabular}

\section{- Results and Discussion}

Figs. (5 and 6) show the effect of frequency (F) on the percentage error in detecting the length and depth respectively of different discontinuities. From the results; the length and depth measuring accuracy improved by increasing frequency.

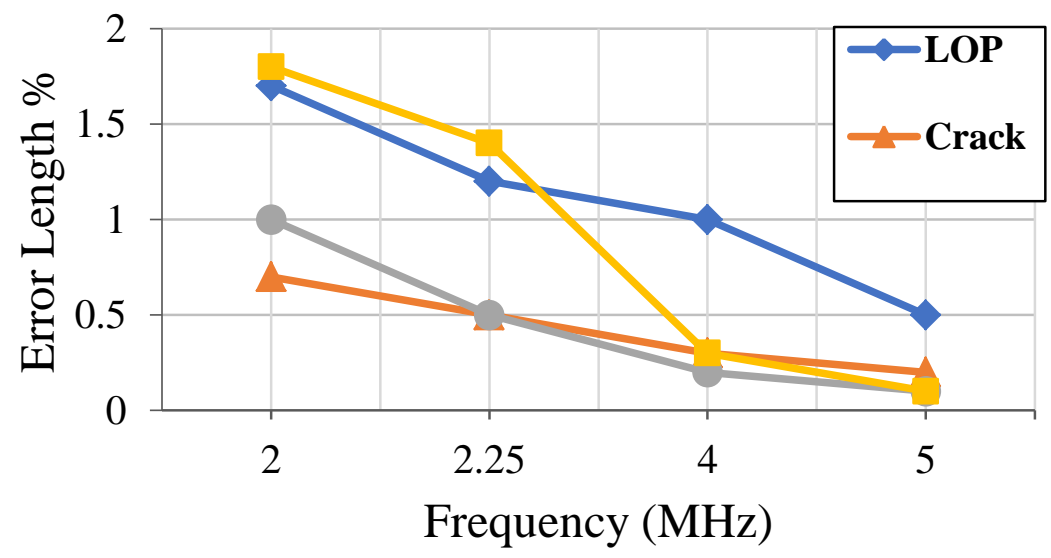

Fig.(5) Relation between Frequency readings vs. Discontinuities error Length. 


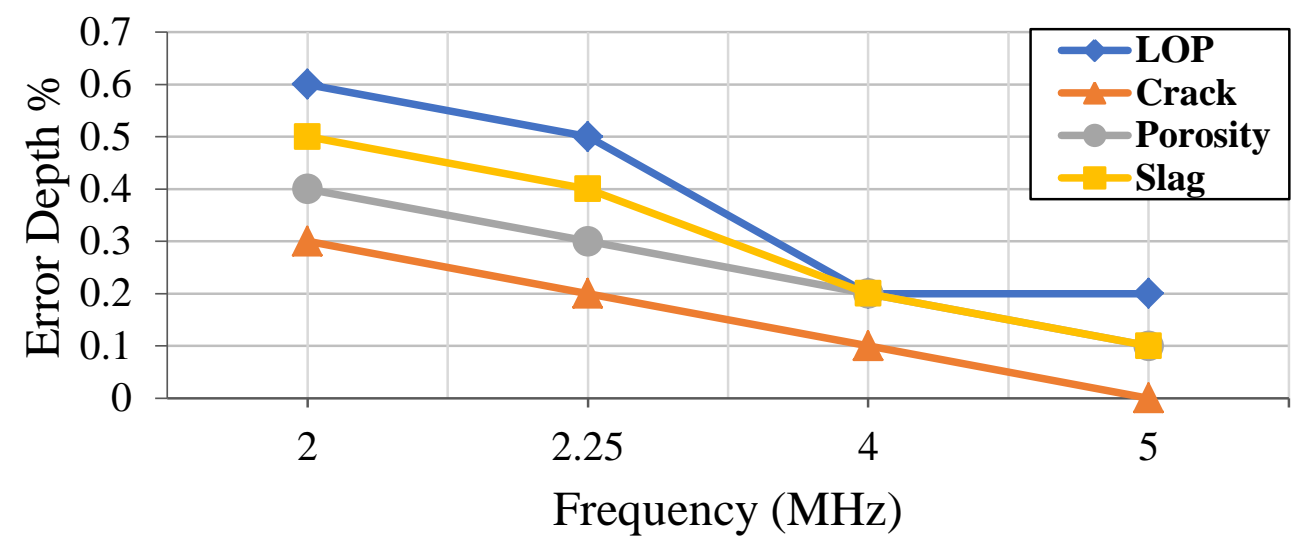

Fig.(6) Relation between Frequency readings vs. Discontinuities error Depth.

\subsection{Effect of number of elements (n)}

In the experiments of discontinuities measurements (length and depth), four experiments $(8,16,32 \& 64)$ piezoelectric elements were carried out, at thickness = $20 \mathrm{~mm}$, frequency $=4 \mathrm{MHz}$, velocity $=5920 \mathrm{~m} / \mathrm{s}$, e (element width $)=0.5 \mathrm{~mm}, \rho($ pitch $)$ $=0.5 \mathrm{~mm}, \mathrm{~g}$ (element gap) $=0.1 \mathrm{~mm}$.

The length/depth readings are listed in Table (3) :

Table (3) The length readings for $N$ (number of elements) $=(8,16,32$ and 64) piezoelectric elements.

\begin{tabular}{|c|c|c|c|c|c|}
\hline \multicolumn{2}{|r|}{ Discontinuity Type } & 8 & 16 & 32 & 64 \\
\hline \multirow{4}{*}{ (2) Crack } & Length Reading (9mm) & 9.5 & 9.4 & 9.4 & 9.1 \\
\hline & Error L & +0.5 & +0.4 & +0.4 & +0.1 \\
\hline & Depth Reading (6.5mm) & 7.1 & 7 & 6.7 & 6.6 \\
\hline & Error D & +0.6 & +0.5 & +0.2 & +0.1 \\
\hline \multirow{4}{*}{ (3) Porosity } & Length Reading (24mm) & 25.2 & 24.9 & 24.5 & 24.4 \\
\hline & Error L & +1.2 & +0.9 & +0.5 & +0.4 \\
\hline & Depth Reading (6.6mm) & 6.2 & 6.2 & 6.3 & 6.5 \\
\hline & Error D & -0.4 & -0.4 & -0.3 & -0.1 \\
\hline \multirow{4}{*}{ (5) Slag } & Length Reading (162mm) & 163.3 & 163.1 & 162.7 & 162.3 \\
\hline & Error L & +1.3 & +1.1 & +0.7 & +0.3 \\
\hline & Depth Reading (5mm) & 4.4 & 4.4 & 4.7 & 4.8 \\
\hline & Error D & -0.6 & -0.6 & -0.3 & -0.2 \\
\hline \multirow{4}{*}{$\begin{array}{l}\text { (17) Lack of } \\
\text { Penetration }\end{array}$} & Length Reading (162mm) & 160.9 & 161.2 & 161.4 & 161.7 \\
\hline & Error L & -1.1 & -0.8 & -0.6 & -0.3 \\
\hline & Depth Reading $(7.1 \mathrm{~mm})$ & 7.5 & 7.5 & 7.3 & 7.1 \\
\hline & Error D & +0.4 & +0.4 & +0.2 & 0 \\
\hline
\end{tabular}




\section{- Results and Discussion}

Figs.(7 and 8) show the effect of the number of piezoelectric elements on the percentage error in detecting the length and depth respectively of different discontinuities. From the results; the length and depth measuring accuracy improved by increasing the number of piezoelectric elements.

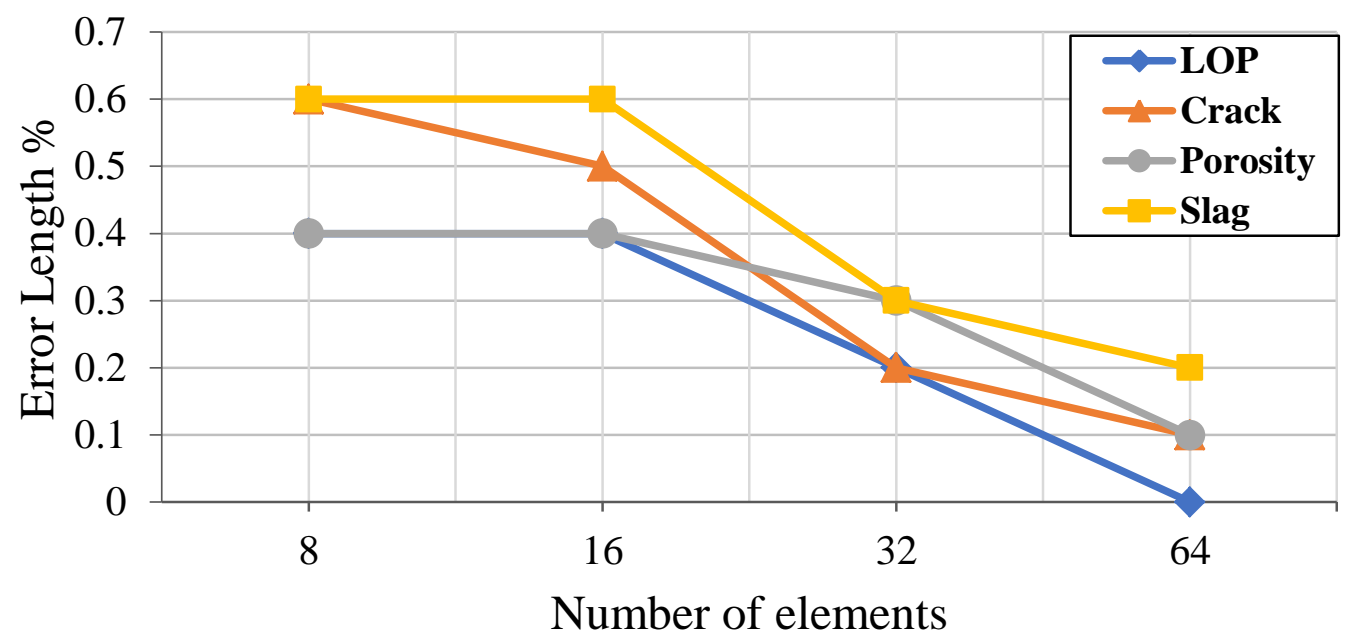

Fig.(7) Relation between number of elements $(\mathrm{N})$ readings vs. Discontinuities error Length.

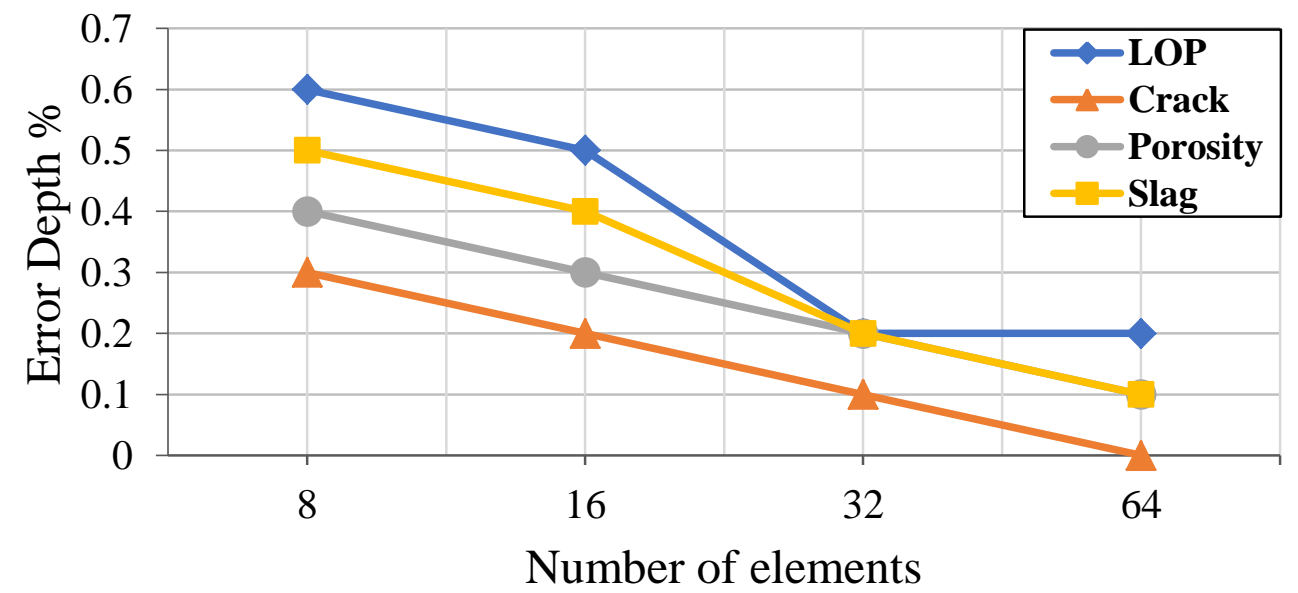

Fig.(8) Relation between number of elements $(\mathrm{N})$ readings vs. Discontinuities error Width.

\subsection{Effect of pitch $(\rho)$}

In the experiments of discontinuities measurements (length and depth), Four experiments $(0.5,1,1.5$ and 2$) \mathrm{mm}$ were carried out, at thickness $=20 \mathrm{~mm}$, frequency $=4 \mathrm{MHz}, \mathrm{N}$ (number of elements) $=16$ piezoelectric element, velocity $=5920 \mathrm{~m} / \mathrm{s}$, e (element width) $=0.5 \mathrm{~mm}, \mathrm{~g}$ (element gap) $=0.1 \mathrm{~mm}$.

The length/depth readings are listed in Table (4) : 
Table (4) The length readings for $\rho(P i t c h)=(0.5,1,1.5$ and 2$) \mathrm{mm}$.

\begin{tabular}{|c|c|c|c|c|c|}
\hline \multicolumn{2}{|r|}{ Discontinuity Type } & $0.5 \mathrm{~mm}$ & $1 \mathrm{~mm}$ & $1.5 \mathrm{~mm}$ & $2 \mathrm{~mm}$ \\
\hline \multirow{4}{*}{ (2) Crack } & Length Reading (9mm) & 8.3 & 8.5 & 8.5 & 8.8 \\
\hline & Error L & -0.7 & -0.5 & -0.5 & -0.2 \\
\hline & Depth Reading $(6.5 \mathrm{~mm})$ & 5.9 & 6 & 6.2 & 6.3 \\
\hline & Error D & -0.6 & -0.5 & -0.3 & -0.2 \\
\hline \multirow{4}{*}{ (3) Porosity } & Length Reading (24mm) & 25.3 & 24.9 & 24.8 & 23.8 \\
\hline & Error L & +1.3 & +0.9 & +0.8 & -0.2 \\
\hline & Depth Reading (6.6mm) & 6.2 & 6.3 & 6.5 & 6.7 \\
\hline & Error D & -0.4 & -0.3 & -0.1 & +0.1 \\
\hline \multirow{4}{*}{ (5) Slag } & Length Reading (162mm) & 162.9 & 162.9 & 162.5 & 162.2 \\
\hline & Error L & +0.9 & +0.9 & +0.5 & +0.2 \\
\hline & Depth Reading (5mm) & 4.3 & 4.5 & 4.5 & 4.6 \\
\hline & Error D & -0.7 & -0.5 & -0.5 & -0.4 \\
\hline \multirow{4}{*}{$\begin{array}{l}\text { (17) Lack of } \\
\text { Penetration }\end{array}$} & Length Reading (162mm) & 161.1 & 161.3 & 161.6 & 161.9 \\
\hline & Error L & -0.9 & -0.7 & -0.4 & -0.1 \\
\hline & Depth Reading (7.1mm) & 6.6 & 6.7 & 6.9 & 7.2 \\
\hline & Error D & -0.5 & -0.4 & -0.2 & +0.1 \\
\hline
\end{tabular}

\section{- Results and Discussion}

Figs. (9 and 10) show the effect of the Pitch $(\rho)$ on the percentage error in detecting the length and depth of different discontinuities. From the results; the length and depth measuring accuracy improved by increasing the Pitch $(\rho)$.

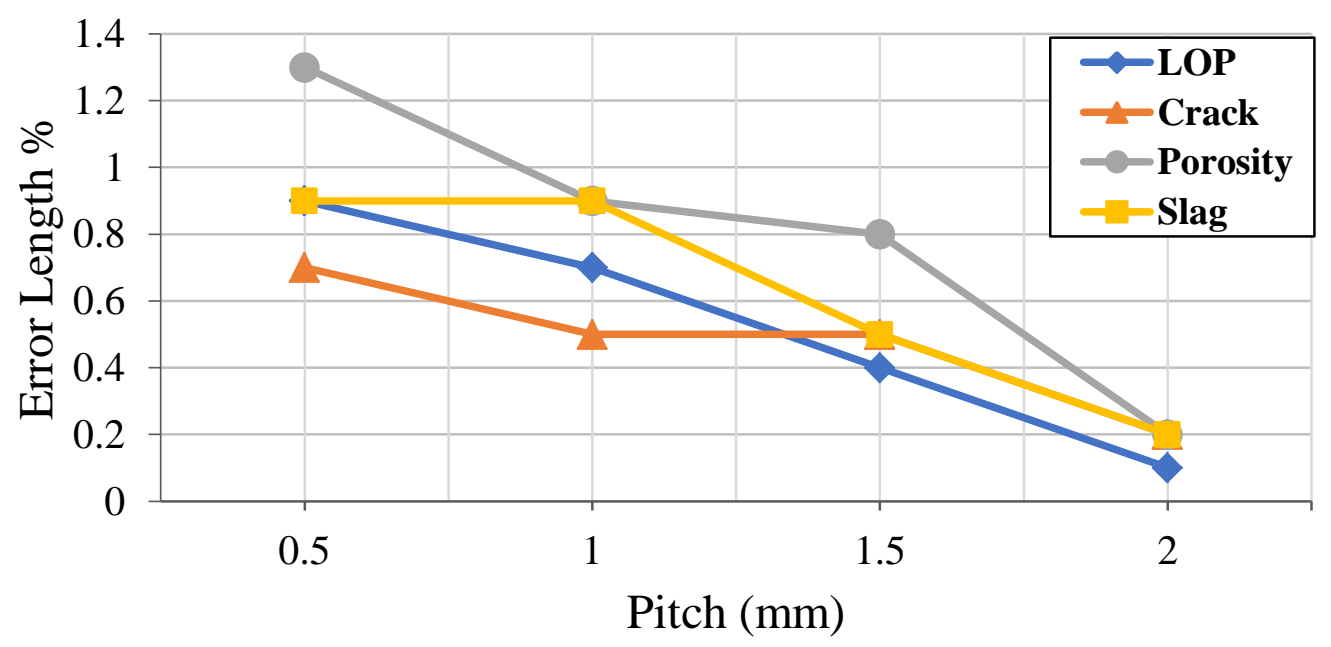

Fig.(9) Relation between Pitch ( $\rho$ ) readings vs. Discontinuities error Length. 


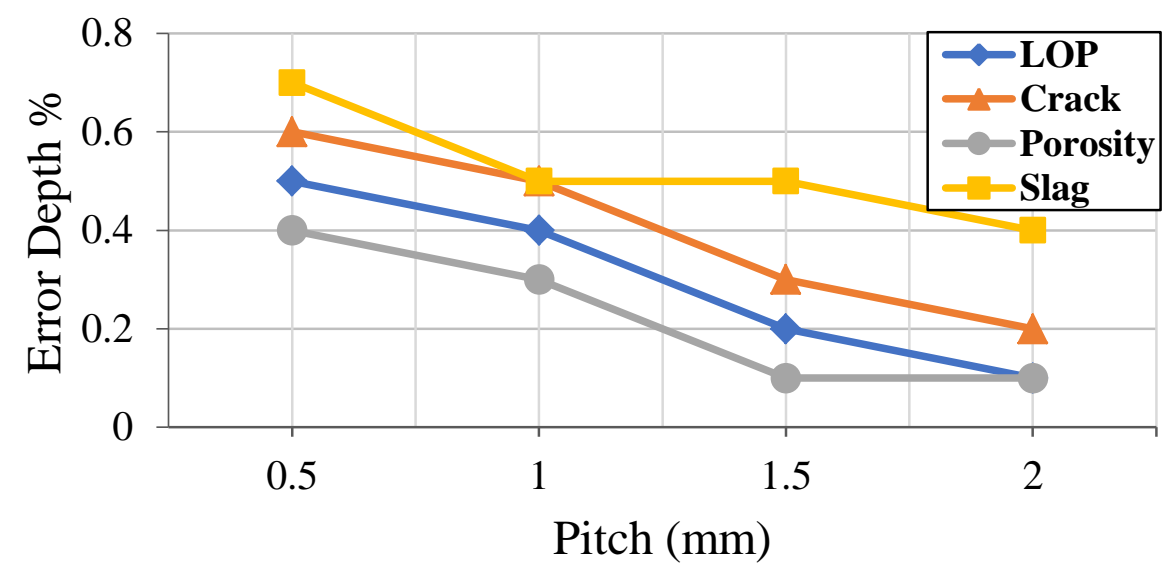

Fig.(10) Relation between Pitch ( $\rho)$ readings vs. Discontinuities error Depth.

\subsection{Factors affecting $R T$ and $U T$ results}

RT, UT and PAUT were conducted to measure the location, length and depth of 5different types of welding discontinuities (1-5) in specimens with thickness ranging from $10-25 \mathrm{~mm}$ - as summarized in Table (5). Discontinuities (1) and (2) were not detected using RT, but using PAUT see Figs. (11 and 12).

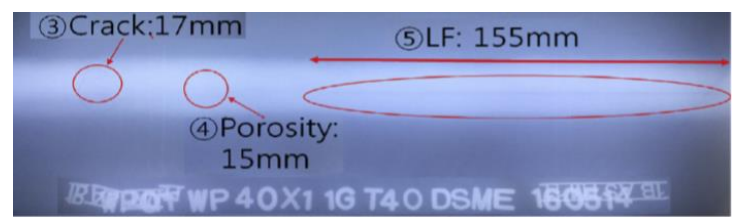

Fig.(11) Radiographic testing results for discontinuities (3) - (5).

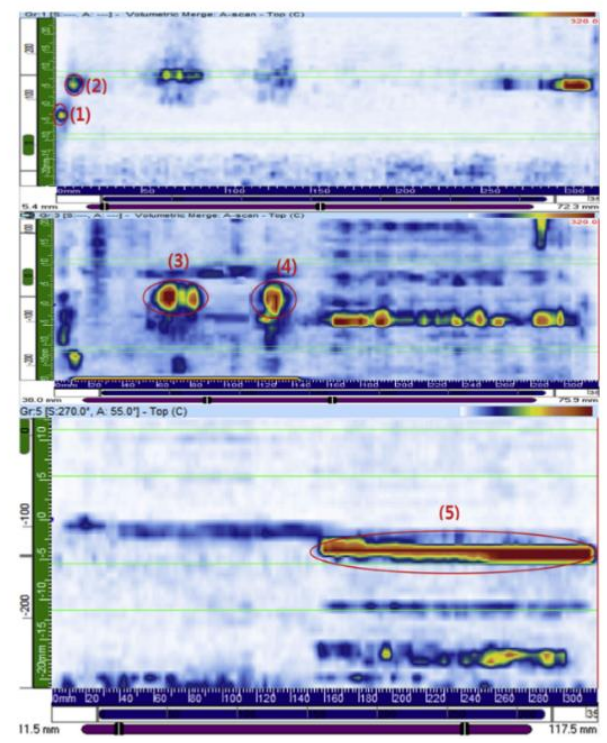

Fig.(12) Phased-array ultrasonic testing (C-Scan) results for discontinuities (1) - (5). 
Table (5) Experimental results of discontinuities (1) - (5) obtained using RT, UT and PAUT.

\begin{tabular}{|c|c|c|c|c|c|}
\hline \multirow{2}{*}{$\begin{array}{c}\text { Discontinuity } \\
\text { Type }\end{array}$} & \multirow{2}{*}{ NDT } & \multirow{2}{*}{$\begin{array}{l}\text { Discontinuity } \\
\text { Length (mm) }\end{array}$} & \multicolumn{2}{|c|}{ Discontinuity Location (mm) } & \multirow{2}{*}{$\begin{array}{c}\text { Discontinuity } \\
\text { Depth (mm) }\end{array}$} \\
\hline & & & $\mathrm{X}$-axis & $\mathrm{Y}$-axis & \\
\hline \multirow{3}{*}{ (1) IP } & RT & undeteceted & & & \\
\hline & PAUT & 6.0 & 0.0 & -3.4 & 4.5 \\
\hline & UT & $4.0-5.0$ & 0.0 & -3.0 & $4.5-5.5$ \\
\hline \multirow{3}{*}{ (2) IP } & RT & undeteceted & & & \\
\hline & PAUT & 9.0 & 6.0 & 4.4 & 6.5 \\
\hline & UT & $4.0-5.0$ & 6.2 & 4.2 & $4.5-5.5$ \\
\hline \multirow{3}{*}{ (3) Crack } & RT & 17.0 & 65.0 & unknown & \\
\hline & PAUT & 24.0 & 58.0 & 2.2 & 6.6 \\
\hline & UT & 22.0 & 57.0 & 2.5 & 4.5 \\
\hline \multirow{3}{*}{ (4) Porosity } & RT & 15.0 & 118.0 & unknown & \\
\hline & PAUT & 11.0 & 122.0 & 2.2 & 7.0 \\
\hline & UT & 10.0 & 122.5 & 2.5 & 4.5 \\
\hline \multirow{3}{*}{ (5) $\mathrm{LoF}$} & RT & 155.0 & 165.0 & unknown & \\
\hline & PAUT & 162.0 & 155.0 & -4.0 & 5.0 \\
\hline & UT & 160.0 & 155.0 & -4.5 & 4.5 \\
\hline
\end{tabular}

\section{Image Processing}

The union of pictures from different $\mathrm{S}$-scans is materialized as 3D images (volumetric scans). Taken two types of discontinuities [Lack of Pen. (LOP) \& Long. Crack] as an example of applying 3-D images from different types of views (Top, Front \& Side).

\subsection{Lack of penetration (LOP)}

As shown in Fig.(13) that LOP considering as longitudinal discontinuity at the middle of the weld root and Fig.(14) shows different S-Scan images taken from X-Axis direction every $1 \mathrm{~mm}$ length position.

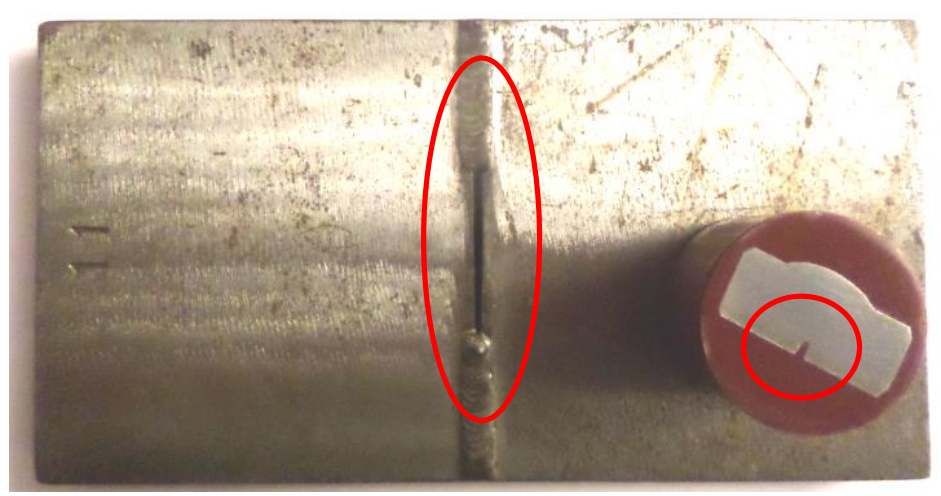

Fig.(13). Photo of LOP standard Discontinuity. 
LOP can be found exactly at the middle of weld root, and it can be characterize as longitudinal and rectangular shape, but the standard division of discontinuity width was low, the echo width was low and the echo height was large (Sharp).
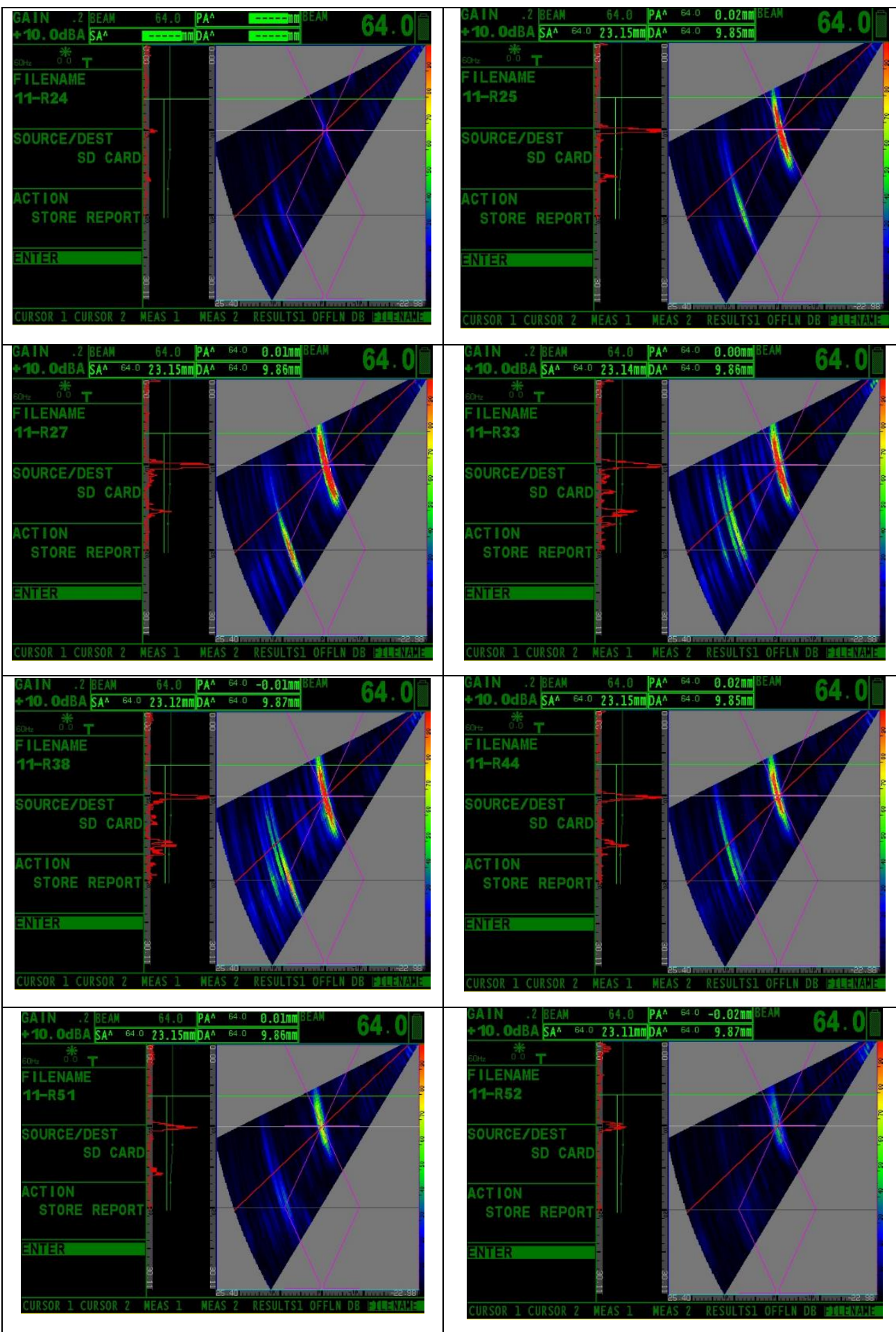

Fig.(14). LOP S-Scans taken respectively to be input to MATLAB Program. 


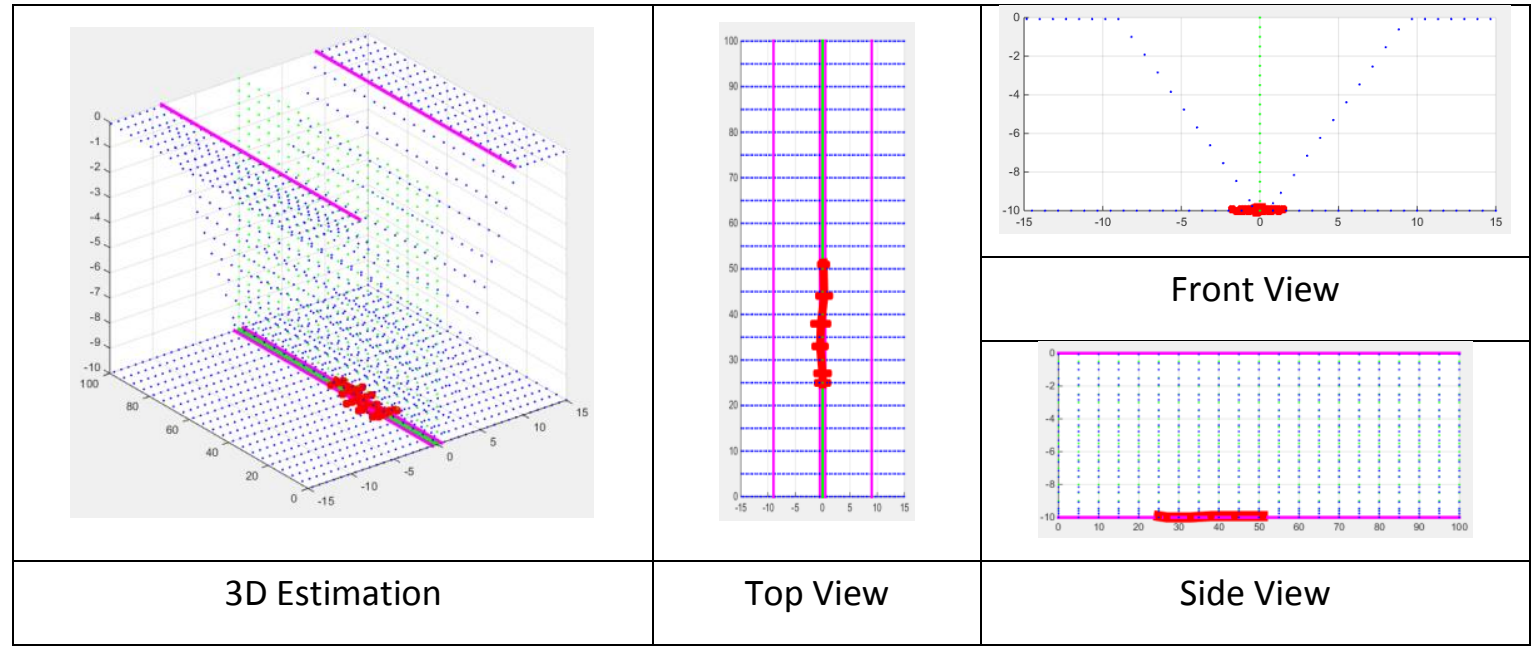

Fig.(15) MATLAP Program output of Lack of Pen. (LOP).

As shown into Fig. (15) above that MATLAP can characterize the LOP into 3D estimation as the photo taken above Fig.(13) at the same location and length.

\subsection{Longitudinal crack}

As shown in Fig.(16) that crack is considered as longitudinal discontinuity at the weld filling and Fig.(17) shows different S-Scan images taken from X-Axis direction every $1 \mathrm{~mm}$ length position.

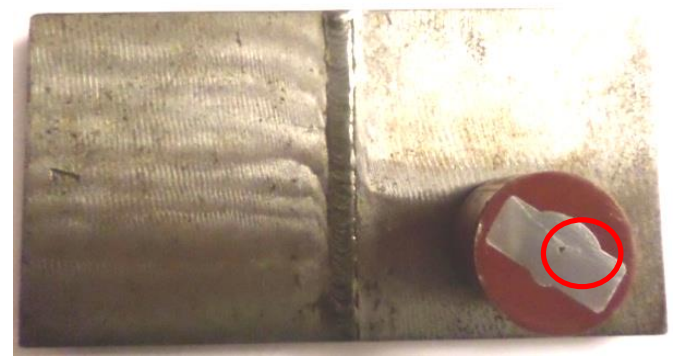

Fig.(16). Photo of LOP standard Discontinuity.

Longitudinal Crack can be found even weld filling or sides, and we it characterize as longitudinal and rectangular shape, the standard division of discontinuity width was low, the echo width and height were large. 


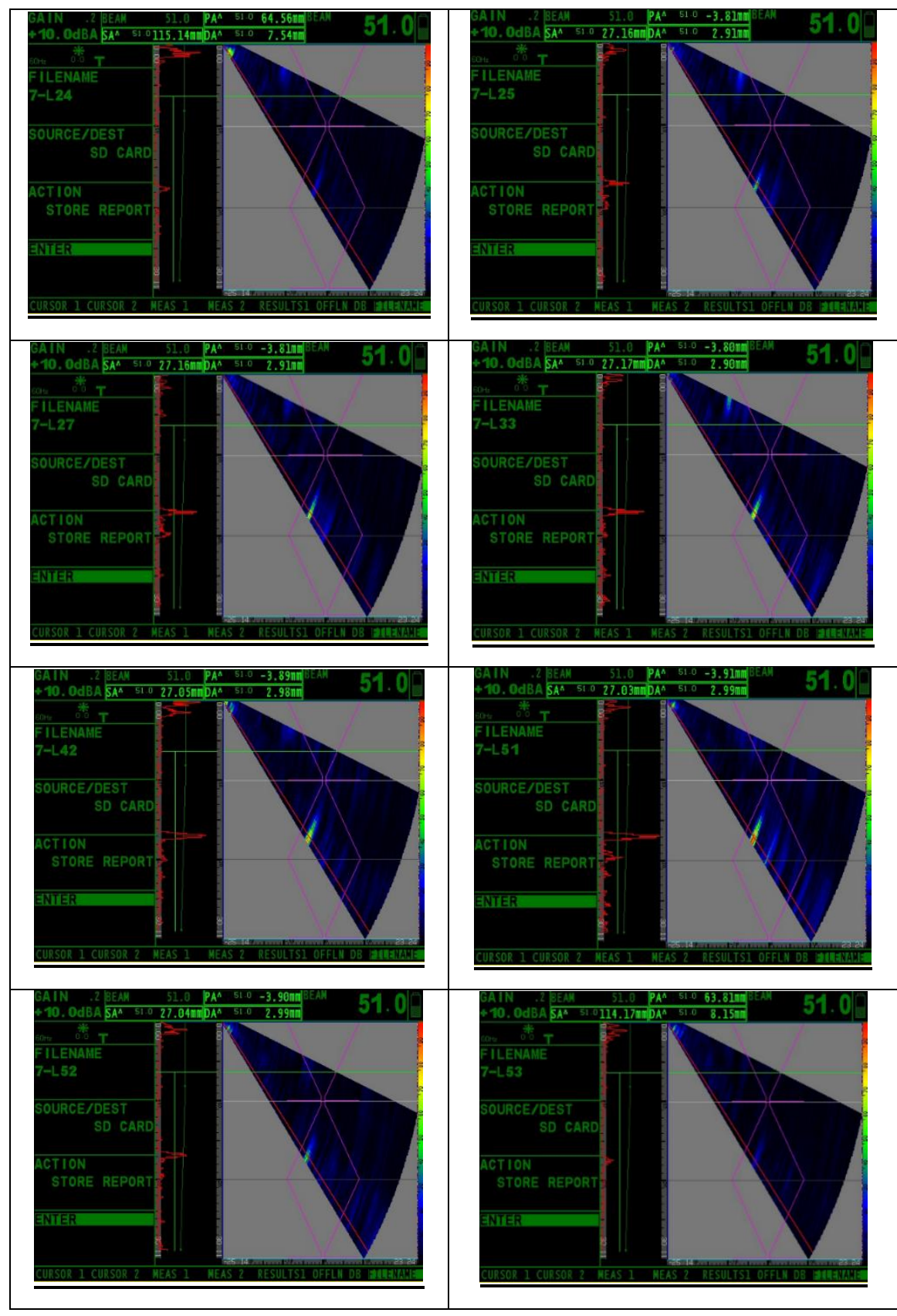

Fig.(17). Crack S-Scans taken respectively to be input to MATLAB Program. 


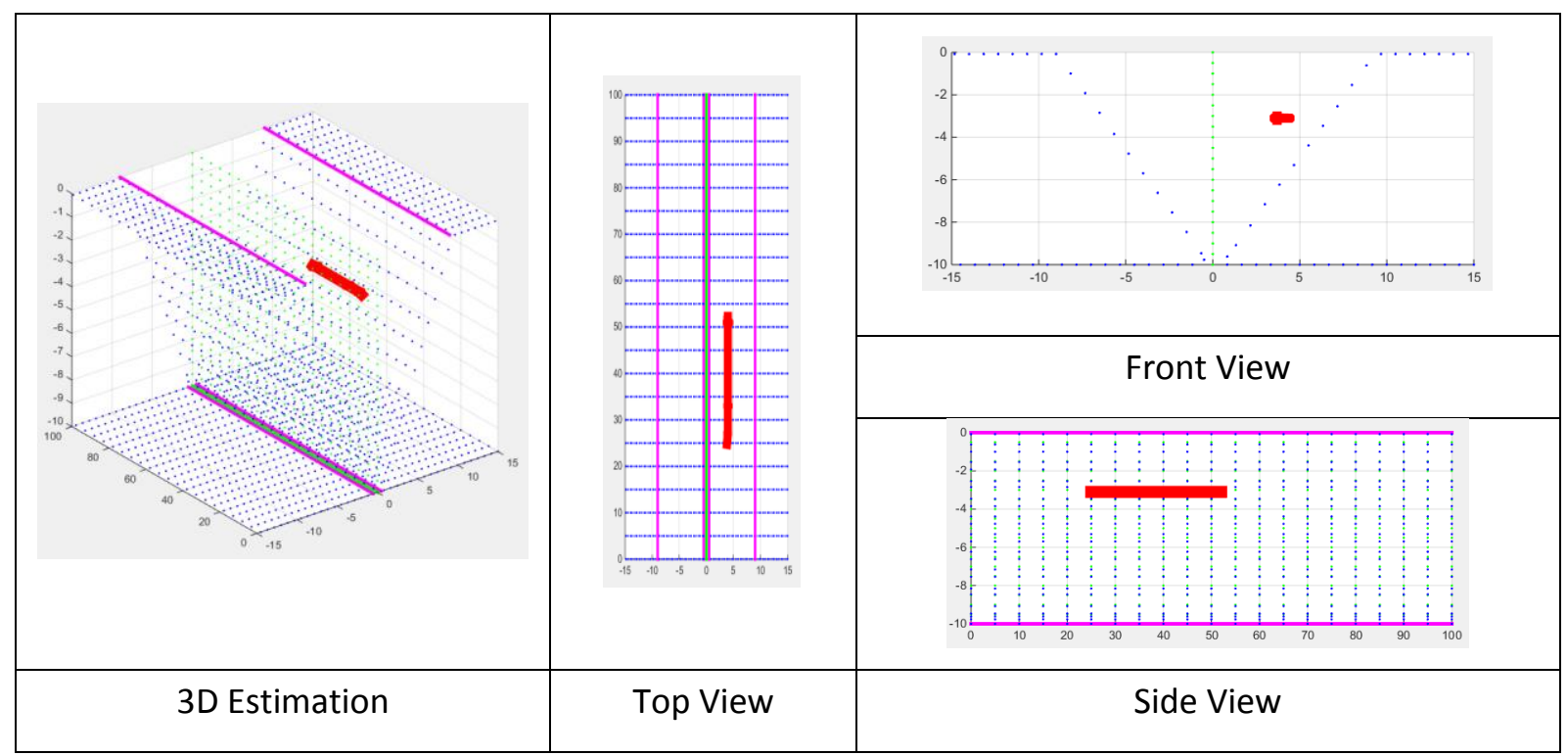

Fig.(30) MATLAP Program output Longitudinal Crack.

As shown into Fig. (18) above that MATLAP can characterize the crack into 3D estimation as the photo taken above Fig.(16) at the same location and length.

\section{Conclusions}

From the experimental work the following points can be concluded :

1. The $6 \mathrm{~dB}$ drop was verified as the most reliable method for measuring the discontinuity length of the welding specimens.

2. Discontinuities length and depth measuring accuracy improved by increasing the frequency, number of piezoelectric elements \& Probe pitch.

3. No discontinuity on radiographic images is not be able to be detected by PAUT especially in detection of subtle welding discontinuities the PAUT is more reliable than RT.

4. Characterization of discontinuity type by using 3D-images (volumetric scan) is more reliable and accurate than 2D-images ( $\mathrm{S}$-scan images).

\section{Future Work}

In order to enhance discontinuity detection capability further, a greater number of piezoelectric elements for the probe will be used, optimization studies on various design variables will be conducted, and additional methods will be developed to calculate clear discontinuity size to further enhance the reliability of soundness evaluation of the welded parts. Applying the artificial intelligent technique to automatic classify welding discontinuities. 


\section{Reference}

(1) Michael Moles, Noel Dube and Ed Ginzel, "Pipeline Girth Weld Inspections Using Ultrasonic Phased Arrays", PANNDT, Rio De Janeiro - Brazil, June (2003).

(2) Michael Moles, Noel Dube and Frederic Jacques "Pressure Vessel Inspections Using Ultrasonic Phased Arrays", 16th World Conference on NDT, Rio de Janeiro, Brazil, June (2003).

(3) Jerome Poirier, Robert Ward, "Qualification of Manual Phased Array Ultrasonic Techniques for Pipe Weld Inspection in Nuclear Power Plants", 17th World Conference on Nondestructive Testing, Shanghai-China, October (2008).

(4) Mmabatho Bokaba, Ngeletshedzo Netshidavhini, Raymond B. Mabuza, "Demonstration of the Capability of Phased Array Technique for Detecting Defects in Thick-Section Welds", 18th World Conference on Nondestructive Testing, Durban, South-Africa, April (2012).

(5) Fereidoon Marefat, M. Reza Faghedi, A. Reza Khodabandeh, "Capabilities and Limitations of Radiography and Phased Array Ultrasonic Test in the Detection of Subtle Welding Defects", Singapore International NDT Conference \& Exhibition, November (2011).

(6) Min-jae Jung, Byeong-cheol Park, Jeong-hoon Bae, "PAUT Based Defect Detection Method for Submarine Pressure Hulls", International Journal for Naval Architecture and Ocean Engineering, Vol.(10), pp; 153-169, (2018). 